\title{
Combined simultaneous transcranial and transsphenoidal resection of large-to-giant pituitary adenomas
}

\author{
Gilberto Ka Kit Leung • Hing Yu Law • \\ Kwun Ngai Hung • Yiu Wah Fan • Wai Man Lui
}

Received: 30 January 2011 / Accepted: 8 April 2011 /Published online: 30 April 2011

(C) The Author(s) 2011. This article is published with open access at Springerlink.com

\begin{abstract}
Background While large-to-giant pituitary adenomas (PAs) may be safely removed by experienced surgeons through a single route, the procedure is technically challenging. We present the outcome of a simultaneous combined transcranial and transsphenoidal approach and discuss its applications.

Methods A retrospective review was conducted on 12 consecutive patients. Surgical complications, visual and endocrinological functions, and tumour control were reviewed. Results There were four men and eight women, with a mean age of 47.6 years. All but one patient had nonfunctioning PAs. The mean tumour height was $4.1 \mathrm{~cm}$ (range: 2.3-5.5). The predominant presenting symptoms were visual field loss in eight patients, headache in three patients and mental confusion in one patient. There was no operative mortality. Post-operative cerebrospinal fluid leakage occurred in one patient. Five of the eight patients who presented with visual field loss achieved full recovery, and three had partial improvement. Two patients developed permanent diabetes insipidus after surgery. Panhypopituitarism occurred in one patient. Gross total removal (GTR) was achieved in five, and subtotal removal (STR) in seven patients. Seven patients received post-operative external irradiation. All patients who had GTR remained tumourfree and all those with STR had stable diseases after a mean follow-up period of 53.1 months (range: 14.1-92.1).
\end{abstract}

G. K. K. Leung $(\bowtie) \cdot$ H. Y. Law $\cdot$ K. N. Hung $\cdot$ Y. W. Fan $•$

W. M. Lui

Division of Neurosurgery, Department of Surgery,

Li Ka Shing Faculty of Medicine, The University of Hong Kong,

Queen Mary Hospital,

102 Pokfulam Road,

Hong Kong SAR, China

e-mail: gilberto@hkucc.hku.hk
Conclusion The simultaneous 'above and below' approach is a safe and effective surgical strategy for large-to-giant PAs, particularly when expertise in endoscopic transsphenoidal surgery is unavailable. Its use, however, should be limited to a carefully selected group of patients, and tailored to individual user's expertise and experience.

Keywords Pituitary adenoma $\cdot$ Transsphenoidal . Craniotomy $\cdot$ Surgical approach $\cdot$ Complications

\section{Introduction}

Surgery for large-to-giant pituitary adenomas (PAs) is technically challenging. Although the transsphenoidal approach has been widely adopted as a safe and effective method for the removal of the majority of PAs, large lesions may still present with considerable difficulties $[1,5,8,12$, 13, 35]. Some of the large PAs may have a fibrous consistency or an 'hour-glass' configuration, rendering complete removal through the transsphenoidal route alone difficult and hazardous. With incomplete removal, a residual suprasellar tumour mass may be complicated by haemorrhages at the early post-operative period, resulting in acute hydrocephalus or optic nerve compression. The transcranial approach is effective for the removal of a suprasellar tumour mass but provides only limited visualization of the intrasellar region. Since some of the large PAs may be highly vascular, a direct transcranial attack may be associated with significant bleeding within the intradural space. Previous studies have reported high operative mortality and morbidity rates using the transsphenoidal or the transcranial approach alone $[9,14,31,32]$.

Several alternative approaches have been described, including the extended endoscopic transsphenoidal approach 
$[4,17]$, the staged transsphenoidal approach [1], the staged transcranial-transsphenoidal approach [2], the combined endoscopic transsphenoidal transventricular approach [10, 24, 25], and the simultaneous combined transcranial and transsphenoidal approach $[2,7,19]$. The latter, in particular, has the advantage of achieving radical tumour removal in a single setting of general anaesthesia. We report our experiences with this simultaneous 'above and below' technique, and discuss its advantages and limitations.

\section{Materials and method}

A retrospective study was conducted on 12 consecutive patients who underwent simultaneous combined microscopic transsphenoidal and transcranial surgery for the removal of PAs between January 2000 and December 2008. The diagnosis of PA was made on magnetic resonance imaging (MRI) and confirmed histologically. All giant PAs ( $>4 \mathrm{~cm}$ in height) were approached with this technique during the study period. For large PAs ( $>2 \mathrm{~cm}$ and $<4 \mathrm{~cm}$ in height), this approach was used when there was significant lateral suprasellar or third ventricular tumour extension, and/or an hourglass configuration.

The anatomical classification of PA described by Wilson et al. [34] was adopted. The relationship of the PA to the sella and sphenoidal sinus was graded as I (normal sella), II (enlarged sella), III (localized sellar perforation), IV (diffuse sellar destruction), and $\mathrm{V}$ [cerebrospinal fluid (CSF) or blood-borne spread]. Extrasellar extension was staged as 0 (none), A (occupying cistern), B (third ventricular obliteration), $\mathrm{C}$ (grossly displaced third ventricle), D (intracranial parasellar extension), and E (extradural parasellar extension).

Patients' pre-operative and post-operative (6-month) visual and endocrinological functions, and surgical complications were reviewed. The first follow-up MRI was performed three months after surgery. Gross total removal (GTR) and subtotal removal (STR) were defined as the absence or presence of contrast-enhancing lesions on the first post-operative MRI, respectively. Thereafter, MRI was performed 12-monthly for patients with GTR, and 6monthly for those with STR. Tumour control and the patients' Karnofsky Performance Score (KPS) were assessed upon the latest follow-up.

\section{Surgical technique}

The tumour was approached both transcranially and transsphenoidally under a single setting of general anaesthesia. Prophylactic broad spectrum antibiotics (ceftriaxone and metronidazole) were given on induction and continued for 3 days post-operatively. Each of the transsphenoidal and transcranial phases had its own surgeon, scrub nurse, operating microscope and set of instruments. The transsphenoidal surgeon stood on the right side of the patient while the transcranial surgeon was seated at the head end. The two operative fields were separate by a vertical drape to minimize contamination.

The transcranial approach was conducted through the anterior interhemispheric route (ten patients) or the subfrontal route (two patients). The patient's head was positioned using a Mayfield clamp in the neutral position for the former, or turned to the side for the latter. The transsphenoidal phase was performed using either the sublabial transseptal route (ten patients) or the transnasal route (two patients).

After the initial opening, two operating microscopes were brought into position (Fig. 1). The tumour was exposed on the cranial side, but every effort was made to avoid breaching the tumour capsule in order to minimize the amount of bleeding within the subarachnoid space. The cranial surgeon's role was to deliver the tumour down towards the sphenoidal sinus, to dissect the tumour capsule from adjacent intradural structures, and to protect the latter against the transsphenoidal surgeon's manipulations, which may at times extend well up rostrally. The tumour capsule was opened on the transsphenoidal side, followed by tumour debulking with suction and curettage. In all of our cases, the intrasellar and intradural tumour bulks were removed completely. Figure 2 illustrates tumours that were removed using this technique.

The subsequent skull base defect was repaired with abdominal fat graft. Again, the cranial surgeon served to prevent against over-enthusiastic packing by the transsphenoidal surgeon. The rest of wound closure was performed in the standard manner. A subgaleal suction

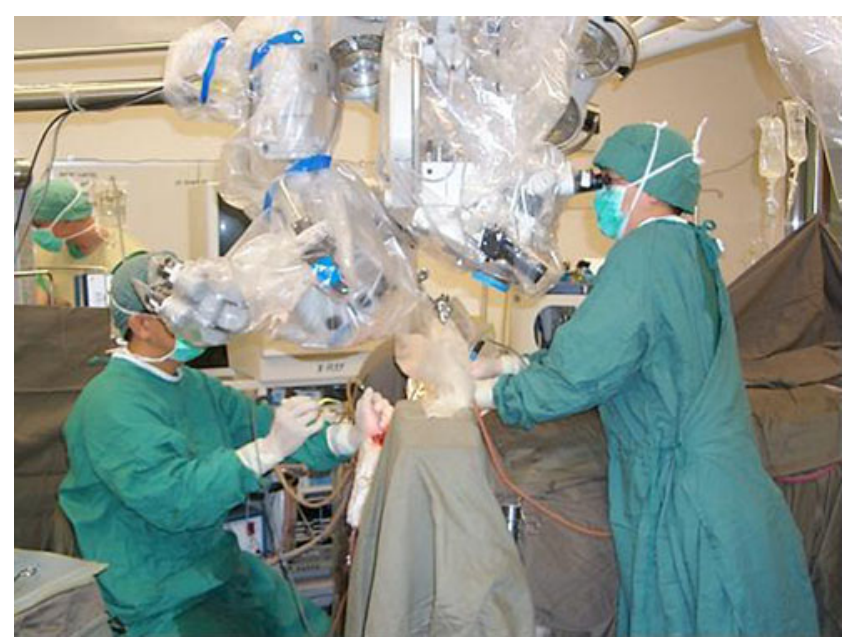

Fig. 1 The setting in the operating room, with two microscopes positioned to allow the simultaneous participation of the transcranial and transsphenoidal surgeons 
Fig. 2 Pre-operative contrasted T1-weighted MRI studies illusmoved using the combined technique. The patient numbers correspond to those in Table 1. a Patient 4, b patient 5, c patient 9 , d patient 11 , e patient 12 trating tumours which were re-
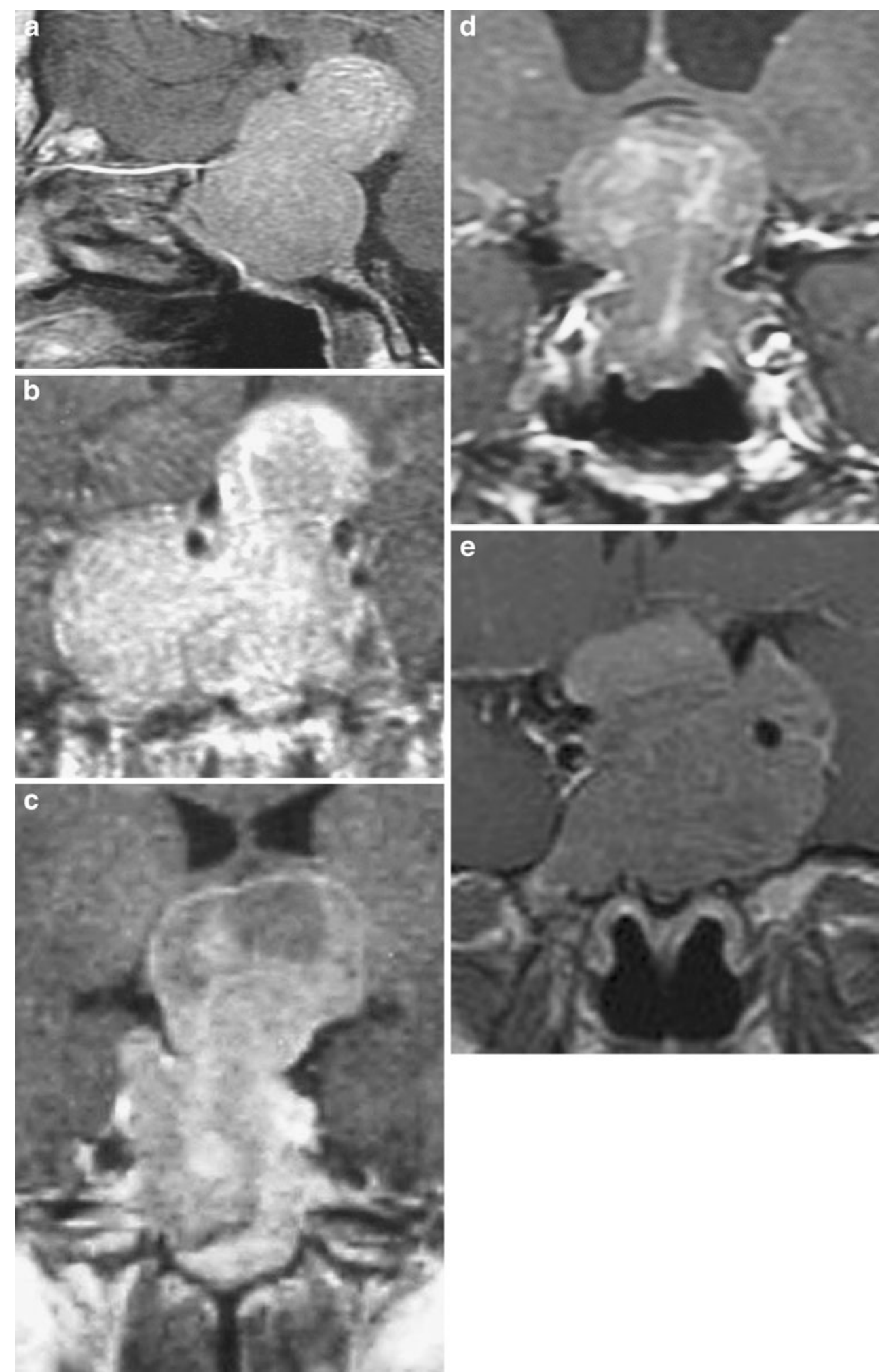

drain was inserted on the cranial side, and the nasal passages were packed for one to two days. No lumbar drain was used. All patients received post-operative care in the intensive care unit. Except for those patients who had previous irradiation therapy, all were offered post-operative fractionated external irradiation as adjuvant treatment.

\section{Results}

Patient characteristics

There were four $(33.3 \%)$ men and eight $(67.7 \%)$ women, with a mean age of 47.6 years (range: $32-79)$ (Table 1). 
Table 1 Patient characteristics and operative procedures

\begin{tabular}{|c|c|c|c|c|c|c|c|c|}
\hline $\begin{array}{l}\text { Patient } \\
\text { no. }\end{array}$ & $\begin{array}{l}\text { Sex/age } \\
\text { (years)/ }\end{array}$ & Symptoms & $\begin{array}{l}\text { Tumor size } \\
(\mathrm{cm})^{\mathrm{a}}\end{array}$ & $\begin{array}{l}\text { Tumor } \\
\text { grade }^{\text {b }}\end{array}$ & $\begin{array}{l}\text { Cranial } \\
\text { approach }\end{array}$ & $\begin{array}{l}\text { Transsphenoidal } \\
\text { approach }\end{array}$ & $\begin{array}{l}\text { Extent of } \\
\text { removal }\end{array}$ & $\begin{array}{l}\text { Operation time } \\
\text { (mins) }\end{array}$ \\
\hline 1 & $\mathrm{~F} / 54$ & BTH & $3.0 \times 3.2 \times 4.5$ & III C & $\mathrm{AIH}$ & Sublabial & GTR & 420 \\
\hline 2 & $\mathrm{~F} / 45$ & HA & $2.9 \times 2.5 \times 4.4$ & III E & Subfrontal & Sublabial & STR & 360 \\
\hline 3 & $\mathrm{M} / 41$ & HA & $2.8 \times 2.3 \times 2.3$ & III D & Subfrontal & Sublabial & GTR & 400 \\
\hline 4 & $\mathrm{M} / 62$ & BTH & $3.0 \times 4.1 \times 5.2$ & III D & $\mathrm{AIH}$ & Sublabial & GTR & 380 \\
\hline 5 & $\mathrm{~F} / 62$ & Acromegalic features, BTH & $3.3 \times 2.6 .3 .6$ & III E & $\mathrm{AIH}$ & Sublabial & STR & 460 \\
\hline 6 & $\mathrm{M} / 47$ & $\mathrm{HA}$ & $3.0 \times 3.5 \times 5.5$ & IIIE & $\mathrm{AIH}$ & Sublabial & STR & 370 \\
\hline 7 & $\mathrm{~F} / 32$ & BTH & $3.0 \times 3.7 \times 3.1$ & III E & $\mathrm{AIH}$ & Transnasal & STR & 380 \\
\hline 8 & $\mathrm{~F} / 65$ & BTH & $3.2 \times 2.2 \times 2.9$ & III E & $\mathrm{AIH}$ & Sublabial & STR & 350 \\
\hline 9 & $\mathrm{~F} / 58$ & BTH & $3.3 \times 2.2 \times 5.0$ & IV C & $\mathrm{AIH}$ & Sublabial & GTR & 450 \\
\hline 10 & $\mathrm{~F} / 52$ & BTH & $3.6 \times 4.4 \times 4.6$ & IV E & $\mathrm{AIH}$ & Sublabial & STR & 210 \\
\hline 11 & $\mathrm{M} / 79$ & Confusion & $2.0 \times 1.8 . \times 2.8$ & III C & $\mathrm{AIH}$ & Transnasal & GTR & 300 \\
\hline 12 & $\mathrm{~F} / 34$ & ВTH & $3.7 \times 3.6 \times 5.3$ & IV E & AIH & Sublabial & STR & 360 \\
\hline
\end{tabular}

AIH anterior interhemispheric, BTH bitemporal hemianopia, GTR gross total removal, HA headache, RT external radiotherapy, STR subtotal removal

${ }^{\text {a }}$ Width $\times$ length $\times$ height

${ }^{\mathrm{b}}$ Modified Hardy's grading staging

Eleven patients had non-functioning PAs and one had a growth-hormone-secreting tumour. The mean tumour height was $4.1 \mathrm{~cm}$ (range: $2.3-5.5$ ). Nine were grade III tumours and three were grade IV tumours. The numbers of stage C, D and E tumours were three, two and seven, respectively. Three cases were recurrent tumours with previous transsphenoidal surgery and radiotherapy performed. The predominant presenting symptoms were visual field loss in eight, headache in three, and mental confusion in one patients.

\section{Operative procedures and complications}

The transcranial approach was anterior interhemispheric in ten patients and subfrontal in two patients (Table 2). The transsphenoidal approach was sublabial transseptal in ten patients and transnasal in two patients. The mean operation time was 370 min (range: $210-460$ ).

There was no operative mortality. One patient died 28 months after surgery due to an unrelated cause. One patient (8.3\%) had post-operative CSF leakage, which was successfully treated with lumbar drainage. One patient (8.3\%) developed deep vein thrombosis without pulmonary complication, and was successfully managed with an inferior vena caval filter and anticoagulation. No patient suffered from meningitis, hydrocephalus or new onset of cranial nerve palsy.

Of all eight patients who presented with visual field loss, five $(62.5 \%)$ achieved full visual field recovery, and three $(37.5 \%)$ had partial improvement. None experienced worsening of vision. All four patients who presented with headache and confusion had symptomatic improvement after surgery. Four patients developed diabetes insipidus (DI) after surgery-two were transient (16.7\%) and two permanent (16.7\%). Panhypopituitarism occurred in one patient. Three other patients had new onset of isolated anterior pituitary deficiencies. All patients had KPS of 70 or above upon the last follow-up.

\section{Tumour control}

Based on the first post-operative MRI, GTR was achieved in five (41.7\%, all stage C or D lesions), and STR in seven patients $(58.3 \%$, all stage $\mathrm{E}$ lesions). Three patients received previous external radiotherapy and were not offered further irradiation. Of the remaining nine patients, seven received post-operative fractionated external irradiation and two declined it. The mean follow-up period was 53.1 months (range: 14.1-92.1). Upon the last follow-up, all five patients who had GTR remained tumour-free, whilst all patients with STR had stable residual diseases. The one patient with acromegaly had STR and continued to receive bromocriptine for biochemical control.

\section{Discussion}

Large and giant PAs are difficult to remove safely. The operative mortality rates have been reported to be as high as $25 \%$ for transcranial resection and $14 \%$ for transsphenoidal resections [31]. Advancement in neurosurgical techniques has led to an improvement in outcome. Sinha et al. [28] 
Table 2 Patients' post-operative outcome

\begin{tabular}{|c|c|c|c|c|c|c|c|c|}
\hline $\begin{array}{l}\text { Patient } \\
\text { no. }\end{array}$ & $\begin{array}{l}\text { Visual } \\
\text { function }\end{array}$ & $\begin{array}{l}\text { New permanent } \\
\text { hormonal deficit }\end{array}$ & $\begin{array}{l}\text { Surgical } \\
\text { complication }\end{array}$ & $\begin{array}{l}\text { Post- } \\
\text { op RT }\end{array}$ & $\begin{array}{l}\text { Tumour } \\
\text { status }\end{array}$ & KPS & $\begin{array}{l}\text { FU duration } \\
\text { (months) }\end{array}$ & Remarks \\
\hline 1 & Normal & $\mathrm{DI}, \downarrow \mathrm{ACTH}$ & None & Yes & $\begin{array}{l}\text { Tumour- } \\
\text { free }\end{array}$ & 90 & 109 & None \\
\hline 2 & Normal & None & None & No & $\begin{array}{l}\text { Stable } \\
\text { residue }\end{array}$ & 90 & 104 & $\begin{array}{l}\text { Recurrence after previous } \\
\text { transsphenoidal removal and RT }\end{array}$ \\
\hline 3 & Normal & None & None & No & $\begin{array}{l}\text { Tumour- } \\
\text { free }\end{array}$ & 90 & 105 & $\begin{array}{l}\text { Recurrence after previous } \\
\text { transsphenoidal removal and RT }\end{array}$ \\
\hline 4 & Normal & DI & None & Yes & $\begin{array}{l}\text { Tumour- } \\
\text { free }\end{array}$ & 80 & 28 & $\begin{array}{l}\text { Died } 28 \text { months later from unrelated } \\
\text { cause }\end{array}$ \\
\hline 5 & $\begin{array}{l}\text { Residual left } \\
\text { HeAn }\end{array}$ & Panhypopituitarism & None & Yes & $\begin{array}{l}\text { Stable } \\
\text { residue }\end{array}$ & 90 & 93 & $\begin{array}{l}\text { Biochemical remission with } \\
\text { bromocriptine }\end{array}$ \\
\hline 6 & Normal & None & CSF leakage & Yes & $\begin{array}{l}\text { Stable } \\
\text { residue }\end{array}$ & 90 & 65 & None \\
\hline 7 & Normal & None & None & No & $\begin{array}{l}\text { Stable } \\
\text { residue }\end{array}$ & 100 & 63 & Patient refused RT \\
\hline 8 & $\begin{array}{l}\text { Improved } \\
\text { BTH }\end{array}$ & None & None & No & $\begin{array}{l}\text { Stable } \\
\text { residue }\end{array}$ & 80 & 55 & $\begin{array}{l}\text { Recurrence after previous } \\
\text { transsphenoidal removal and RT }\end{array}$ \\
\hline 9 & Normal & $\downarrow \mathrm{TSH}$ & $\begin{array}{l}\text { Deep vein } \\
\text { thrombosis }\end{array}$ & Yes & $\begin{array}{l}\text { Tumour- } \\
\text { free }\end{array}$ & 100 & 54 & $\begin{array}{l}\text { Deep vein thrombosis treated with } \\
\text { caval filter. }\end{array}$ \\
\hline 10 & $\begin{array}{l}\text { Residual left } \\
\text { HeAn }\end{array}$ & $\downarrow \mathrm{ACTH}$ & None & Yes & $\begin{array}{l}\text { Stable } \\
\text { residue }\end{array}$ & 100 & 24 & None \\
\hline 11 & Normal & None & None & No & $\begin{array}{l}\text { Tumour- } \\
\text { free }\end{array}$ & 70 & 24 & Patient refused RT \\
\hline 12 & Normal & None & None & Yes & $\begin{array}{l}\text { Stable } \\
\text { residue }\end{array}$ & 100 & 26 & None \\
\hline
\end{tabular}

$A C T H$ adrenocorticotropic hormone, BTH bitemporal hemianopia, $C S F$ cerebrospinal fluid, $D I$ diabetes insipidus, $F U$ follow-up since surgery, $H e A n$ hemianopia, KPS Karnofsky Performance Score, $R T$ external radiotherapy, TSH thyrotropic stimulating hormone

reported the surgical outcomes of 250 patients with giant PAs. Near-total $(>90 \%)$ tumour removal was achieved in $74 \%$ and improvement of vision in $53 \%$ of patients. The mortality and morbidity rates were $4.4 \%$ and $14 \%$, respectively. Xue-Fei et al. [35] treated 54 patients with large PAs using a variety of surgical approaches and achieved complete tumour removal in $21 \%$ of cases. The peri-operative mortality rate was $7.9 \%$. In another series of 111 patients, Mortini et al. [21] reported a mortality rate of $2.7 \%$. The incidences of 'major' complications (e.g. cranial nerves, hypothalamic and vascular injuries, CSF leakages and tumour haemorrhages), and 'minor' complications (e.g. endocrinological) were $18 \%$ and $26 \%$, respectively. Using the same categorization, the incidences of 'major' and 'minor' complications in our present series were comparable at $8.3 \%$ and $25 \%$, respectively. The extent of removal in our series, however, was comparatively lower, which was probably due to our conservative approach towards tumours within the cavernous sinuses.

The transsphenoidal approach is the treatment of choice for the majority of PAs. But for tumours that arise in or extend into the suprasellar region, transsphenoidal surgery is generally contraindicated when there is a normal-sized sella turcica, normal pituitary function, or adherence of the tumour to major intracranial structures $[6,12,14,18]$. A tumour that is fibrous in consistency or has an hour-glass configuration may also be difficult to remove completely with a single transsphenoidal procedure [20]. Lumbar subarachnoid saline or air injection may be used to facilitate the descent of the suprasellar tumour bulk into the sella, but the method is effective only in a subgroup of patients [29, 37]. In a prospective study, Honegger et al. [11] demonstrated that the vertical intracranial extension, and an irregular or multilobular configuration, were significant and independent predictors for incomplete resection. To address this, the two-staged transsphenoidal approach has been advocated, in which, after the removal of the intrasellar tumour component, the suprasellar residual tumour was given time to descend and then removed by a second-stage transsphenoidal procedure [1, 26, 31]. The disadvantages of this approach include the need for two operations and the potential risks of tumour swelling and haemorrhages after the first-stage surgery.

The introduction of endoscopic transsphenoidal surgery has revolutionized the treatment of sellar tumours [4]. It has been shown to be safe and effective, and is now an arguably standard therapy for the majority of PAs. But despite the vastly improved illumination and visualization provided by 
the use of endoscopes, a giant or invasive PA is amenable to a single-stage removal by a limited number of experts only [30]. Wang et al. [33] reported an $80 \%$ total resection rate in a series of 64 patients without mortality or tumour recurrence. Similarly, Sanai et al. [27] reported a GTR rate of close to $50 \%$, with no incidence of CSF leakage, new panhypopituitarism or worsening of vision. Nakao et al. [23] treated 43 patients using the endoscopic endonasal approach and an intracapsular resection technique. Gross total removal was achieved in close to $50 \%$ of cases and there was no major complication. While the indications for endoscopic pituitary surgery are expanding, its use and limits for the treatment of huge PAs are yet to be defined. The extended endoscopic transsphenoidal approach, in particular, is a technically demanding technique. It requires specialized and advanced training, and may not be readily acquired by surgeons without the necessary case volume [4].

For many, the transcranial approach continues to play a role in the management of PAs inaccessible from the transsphenoidal route alone [36]. When compared with the transsphenoidal approach, there is a trend towards greater visual improvement, but the benefit may be offset by a greater risk of post-operative pituitary dysfunction [22]. The disadvantages of the transcranial approach include the amount of brain retraction required and the limited visualization of the intrasellar area $\left[{ }^{15}\right]$. In our experience, a transcranial resection of vascular tumours may also be associated with significant bleeding within the intradural space. This may further obscure the surgical view, and potentially increase the risks of brain swelling and hydrocephalus. One of the advantages of our simultaneous combined approach is that tumour bleeding would occur predominantly on the transsphenoidal side. The transcranial surgeon only serves to deliver the tumour bulk towards the sella, and to protect the intradural structures.

Loyo et al. [19] first described the combined supra-sellar and infra-sellar approach in 1984 for the resection of very large PAs, and advocated it as superior to either the transsphenoidal or the intracranial approach alone. Case reports on the use of the 'above and below' approach for a large craniopharyngioma [16], and a PA with lateral ventricle extension have been described [10]. To our knowledge, there are two reported case series on the combined approach for large-to-giant PAs. Alleyne et al. [2] reported a GTR rate of $40 \%$ in a cohort of ten patients. More than half of those who presented with pre-operative visual field loss experienced complete recovery. Permanent DI occurred in $20 \%$ of patients. In D'Ambrosio et al.'s series [7], GTR was achieved in six out of 11 patients $(55 \%)$. Seven patients $(64 \%)$ experienced visual improvement post-operatively and no major complication occurred. Panhypopituitarism was observed in four and persistent DI in two patients. The authors of these two series focused mainly on early operative outcomes but not tumour control. Our present study yielded similar early outcomes. In addition, we were also able to demonstrate satisfactory medium-term tumour control. Admittedly, the use of upfront fractionated external irradiation, instead of radiosurgery, in our series warrants careful scrutiny in view of the former's potential side-effects. This is a limitation of our treatment paradigm that needs to be improved.

Conceptually, we consider this technique to be a posterior extension of that of craniofacial resection for anterior skull base tumours, in that lesions which occupy two adjoining skull base compartments are best approached simultaneously from both compartments for maximal tumour removal and safety [15]. Although pathologically very different, these two disease groups may exhibit similar morphological features, such as close adherence to intracranial structures, irregular configurations and extensive skull base destruction. Technically, we favour the anterior inter-hemispheric route for the transcranial phase because it provides a better view of the parasellar region bilaterally. The subfrontal or pterional route, on the other hand, requires some head-turning, which may potentially disorientate the transsphenoidal surgeon.

One of the main goals of surgery for huge PAs is optic nerve/chiasm decompression, for which the combined approach appears to be a safe and effective method. The main advantages of our technique include the need for only one procedure, the protection offered by the transcranial surgeon, and the avoidance of complications potentially caused by any residual suprasellar tumour bulk. The main disadvantages include the involvement of two operative fields, the doubling of staff and instruments required, the long operating time, and the potential complications of a craniotomy. The need for two operating microscopes, however, may be obviated by the use of endoscopes for the transsphenoidal phase of the procedure. More recently, an alternative 'above and below' approach has been described by several authorities for the treatment of PAs with significant third ventricular extensions. It uses a simultaneous endoscopic transsphenoidal-transventricular technique and therefore obviates the need for a craniotomy $[10,24,25]$.

In terms of tumour control, stage C (grossly displaced third ventricle) and D (intracranial parasellar extension) are potentially amenable to total removal with our technique; stage E (extradural parasellar extension) lesions may require a more extensive extradural approach. However, being a retrospective case series, this report may suffer from case selection bias, suboptimal data collection, and the lack of a control cohort for outcome analysis. The optimal treatment of large-to-giant PAs is likely to require a more tailored approach, based on individual patients' conditions and the surgeons' experiences and abilities. A multi- 
modality management strategy should be adopted to take full advantages of the benefits provided by surgery and radiotherapy [8]. The use of intra-operative MRI may also significantly improve resection rate and safety [3]. Our combined approach represents only one of the many surgical strategies that can be used in dealing with these challenging PAs, particularly when expertise in endoscopic surgery is unavailable.

\section{Conclusion}

Large and giant PAs are challenging lesions. Although many experienced surgeons would be able to remove these tumours endoscopically through the transsphenoidal route alone, the necessary expertise is not easy to acquire. The present study demonstrates that the simultaneous transcranial transsphenoidal approach is a safe and feasible alternative. It requires teamwork and more readily available technical skills from the transcranial and transsphenoidal surgeons. Its use, however, should be limited to a carefully selected group of patients, and tailored to individual users' expertise and experiences.

Acknowledgements We thank Miss Gloria K.B. Ng and Mr. Gary Lee for their assistance in preparing this manuscript.

Conflicts of interest None.

Open Access This article is distributed under the terms of the Creative Commons Attribution Noncommercial License which permits any noncommercial use, distribution, and reproduction in any medium, provided the original author(s) and source are credited.

\section{References}

1. Abe T, Iwata T, Kawamura N, Izumiyama H, Ikeda H, Matsumoto K (1997) Staged transsphenoidal surgery for fibrous nonfunctioning pituitary adenomas with suprasellar extension. Neurol Med Chir (Tokyo) 37:830-835; discussion 835-837

2. Alleyne CH Jr, Barrow DL, Oyesiku NM (2002) Combined transsphenoidal and pterional craniotomy approach to giant pituitary tumors. Surg Neurol 57:380-390; discussion 390

3. Baumann F, Schmid C, Bernays RL (2010) Intraoperative magnetic resonance imaging-guided transsphenoidal surgery for giant pituitary adenomas. Neurosurg Rev 33:83-90

4. Cappabianca P, Cavallo LM, Esposito F, De Divitiis O, Messina A, De Divitiis E (2008) Extended endoscopic endonasal approach to the midline skull base: the evolving role of transsphenoidal surgery. Adv Tech Stand Neurosurg 33:151-199

5. Chacko G, Chacko AG, Lombardero M, Mani S, Seshadri MS, Kovacs K, Scheithauer BW (2009) Clinicopathologic correlates of giant pituitary adenomas. J Clin Neurosci 16:660-665

6. Couldwell WT (2004) Transsphenoidal and transcranial surgery for pituitary adenomas. J Neurooncol 69:237-256

7. D'Ambrosio AL, Syed ON, Grobelny BT, Freda PU, Wardlaw S, Bruce JN (2009) Simultaneous above and below approach to giant pituitary adenomas: surgical strategies and long-term follow-up. Pituitary 12:217-225

8. de Paiva Neto MA, Vandergrift A, Fatemi N, Gorgulho AA, Desalles AA, Cohan P, Wang C, Swerdloff R, Kelly DF (2010) Endonasal transsphenoidal surgery and multimodality treatment for giant pituitary adenomas. Clin Endocrinol (Oxf) 72:512-519

9. Goel A, Nadkarni T, Muzumdar D, Desai K, Phalke U, Sharma P (2004) Giant pituitary tumors: a study based on surgical treatment of 118 cases. Surg Neurol 61:436-445; discussion 445-436

10. Greenfield JP, Leng LZ, Chaudhry U, Brown S, Anand VK, Souweidane MM, Schwartz TH (2008) Combined simultaneous endoscopic transsphenoidal and endoscopic transventricular resection of a giant pituitary macroadenoma. Minim Invasive Neurosurg 51:306-309

11. Honegger J, Ernemann U, Psaras T, Will B (2007) Objective criteria for successful transsphenoidal removal of suprasellar nonfunctioning pituitary adenomas. A prospective study. Acta Neurochir (Wien) 149:21-29; discussion 29

12. Jane JA Jr, Laws ER Jr (2001) The surgical management of pituitary adenomas in a series of 3,093 patients. J Am Coll Surg 193:651-659

13. Jane JA Jr, Han J, Prevedello DM, Jagannathan J, Dumont AS, Laws ER Jr (2005) Perspectives on endoscopic transsphenoidal surgery. Neurosurg Focus 19:E2

14. Jeffreys RV (1989) The surgical treatment of large pituitary adenomas. Br J Neurosurg 3:147-152

15. Kabil MS, Jarrahy R, Shahinian HK (2005) The application of craniofacial techniques and intracranial endoscopy to pituitary surgery. J Craniofac Surg 16:812-818

16. Kobayashi S, Takemae T, Sugita K (1984) Combined transsphenoidal and transoral approach for clivus chordoma. No Shinkei Geka 12:1339-1346

17. Laufer I, Anand VK, Schwartz TH (2007) Endoscopic, endonasal extended transsphenoidal, transplanum transtuberculum approach for resection of suprasellar lesions. J Neurosurg 106:400-406

18. Liu JK, Das K, Weiss MH, Laws ER Jr, Couldwell WT (2001) The history and evolution of transsphenoidal surgery. J Neurosurg 95:1083-1096

19. Loyo M, Kleriga E, Mateos H, de Leo R, Delgado A (1984) Combined supra-infrasellar approach for large pituitary tumors. Neurosurgery 14:485-488

20. Mohr G, Hardy J, Comtois R, Beauregard H (1990) Surgical management of giant pituitary adenomas. Can J Neurol Sci 17:6266

21. Mortini P, Barzaghi R, Losa M, Boari N, Giovanelli M (2007) Surgical treatment of giant pituitary adenomas: strategies and results in a series of 95 consecutive patients. Neurosurgery 60:993-1002; discussion 1003-1004

22. Musleh W, Sonabend AM, Lesniak MS (2006) Role of craniotomy in the management of pituitary adenomas and sellar/ parasellar tumors. Expert Rev Anticancer Ther 6(Suppl 9):S79S83

23. Nakao N, Itakura T (2011) Surgical outcome of the endoscopic endonasal approach for non-functioning giant pituitary adenoma. J Clin Neurosci 18:71-75

24. Ojha BK, Husain M, Rastogi M, Chandra A, Chugh A, Husain N (2009) Combined trans-sphenoidal and simultaneous transventricular-endoscopic decompression of a giant pituitary adenoma: case report. Acta Neurochir (Wien) 151:843-847; discussion 847

25. Romano A, Chibbaro S, Marsella M, Oretti G, Spiriev T, Iaccarino C, Servadei F (2010) Combined endoscopic transsphenoidal-transventricular approach for resection of a giant pituitary macroadenoma. World Neurosurg 74:161-164

26. Saito K, Kuwayama A, Yamamoto N, Sugita K (1995) The transsphenoidal removal of nonfunctioning pituitary adenomas with 
suprasellar extensions: the open sella method and intentionally staged operation. Neurosurgery 36:668-675; discussion 675-666

27. Sanai N, Quinones-Hinojosa A, Narvid J, Kunwar S (2008) Safety and efficacy of the direct endonasal transsphenoidal approach for challenging sellar tumors. J Neurooncol 87:317-325

28. Sinha S, Sharma BS (2010) Giant pituitary adenomas — an enigma revisited. Microsurgical treatment strategies and outcome in a series of 250 patients. Br J Neurosurg 24:31-39

29. Spaziante R, de Divitiis E (1989) Forced subarachnoid air in transsphenoidal excision of pituitary tumors (pumping technique). J Neurosurg 71:864-867

30. Tabaee A, Anand VK, Barron Y, Hiltzik DH, Brown SM, Kacker A, Mazumdar M, Schwartz TH (2009) Endoscopic pituitary surgery: a systematic review and meta-analysis. J Neurosurg 111:545-554

31. Takakura K, Teramoto A (1996) Management of huge pituitary adenomas. Acta Neurochir Suppl 65:13-15

32. van Lindert EJ, Grotenhuis JA, Meijer E (1991) Results of followup after removal of non-functioning pituitary adenomas by transcranial surgery. Br J Neurosurg 5:129-133

33. Wang RZ, Yin J, Su CB, Ren ZY, Yao Y, Tao W (2006) Extended transsphenoidal operation for giant and invasive pituitary adenomas. Zhonghua Wai Ke Za Zhi 44:1548-1550

34. Wilson CB (1984) A decade of pituitary microsurgery. The Herbert Olivecrona lecture. J Neurosurg 61:814-833

35. Xue-Fei S, Yong-Fei W, Shi-Qi L, Jing-Song W, Yao Z, Ying M, Liang-Fu Z (2008) Microsurgical treatment for giant and irregular pituitary adenomas in a series of 54 consecutive patients. Br J Neurosurg 22:636-648

36. Youssef AS, Agazzi S, van Loveren HR (2005) Transcranial surgery for pituitary adenomas. Neurosurgery 57:168-175; discussion $168-175$

37. Zhang X, Fei Z, Zhang J, Fu L, Zhang Z, Liu W, Chen Y (1999) Management of nonfunctioning pituitary adenomas with suprasellar extensions by transsphenoidal microsurgery. Surg Neurol $52: 380-385$

\section{Comment}

In managing a huge and multilobed tumour, the surgeon accepts that the now generally adopted transsphenoidal approach is going to run the risk of leaving benign tumour in the suprasellar space and, of course, invading the cavernous sinus and that residual will cause problems with swelling and haemorrhage in a few. The question is how to manage them.

I can accept the occasional need to link cranial and transsphenoidal surgery, but my problem is why there is a need to do them both together, exactly at the same time. Why not do the transsphenoidal and go on, if absolutely necessary, at the same sitting. The transsphenoidal is so quick, and all I could see is the cranial part getting in the way.

Michael Powell

London, UK 